\title{
Genital Micro-Organisms in Pregnancy
}

\author{
Rashmi Bagga ${ }^{1}$ and Parul Arora ${ }^{2 *}$ \\ ${ }^{1}$ Department of Obstetrics \& Gynaecology, Post Graduate Institute of Medical Education \& Research, Chandigarh, India, \\ ${ }^{2}$ Reproductive Medicine, Nova IVF Fertility, Ahmedabad, India
}

OPEN ACCESS

Edited by:

Elena Ambrosino,

Maastricht University, Netherlands

Reviewed by:

Phileno Pinge-Filho,

State University of Londrina, Brazil

Tingtao Chen,

Nanchang University, China

Barbra Richardson,

University of Washington,

United States

*Correspondence:

Parul Arora

drparul20arora@gmail.com

Specialty section:

This article was submitted to Infectious Diseases - Surveillance,

Prevention and Treatment, a section of the journal Frontiers in Public Health

Received: 09 February 2020 Accepted: 14 May 2020 Published: 16 June 2020

Citation:

Bagga R and Arora P (2020) Genital Micro-Organisms in Pregnancy.

Front. Public Health 8:225.

doi: 10.3389/fpubh.2020.00225
The microbiome of the female genital tract may undergo changes in pregnancy due to metabolic, endocrinological, and immunological alterations. These dysbiotic states may cause infections which may ascend upwards to the feto-placental unit or may be seeded hematogenously. These low grade and often low virulent infectious states lead to chronic inflammatory states and maybe associated with adverse maternal and neonatal outcome. Organisms have been isolated from amniotic fluid and placentae from women delivering pre-term; however the possibility of contamination cannot be conclusively ruled out. Common vaginal dysbiotic states often cause symptoms that are overlooked and often untreated. Vulvovaginal Candidiasis (VVC), Bacterial Vaginosis (BV), and Trichomonas Vaginitis (TV) are the commonly occurring dysbiotic states leading to vaginal infective states in pregnancy. With the advent of novel technologies like Next Generation sequencing (NGS), it will soon be possible to comprehensively map the vaginal microbiome and assess the interplay of each microbial state with their effects in pregnancy. This may open new avenues for antibiotic recommendations, probiotics and potential alternate therapies for dysbiotic states leading to pregnancy complications.

Keywords: genital microbiome, dysbiosis, bacterial vaginosis, candidiasis, Trichomonas vaginalis

\section{INTRODUCTION}

It was widely believed that the fetoplacental unit was free of germs and the first exposure of the newborn to microbes occurred during delivery, and not earlier (1). Any bacterial growth in the amniotic fluid or placenta was thought to originate from the lower genital tract and was likely to harm the pregnancy. Bacteria have been shown to traverse the intact materno-fetal membranes and have also been isolated in healthy pregnant women in the amniotic fluid and placentae (2). Recently, microorganisms have been identified in the uterus before conception also (3). It has been suggested that certain obstetrical and neonatal complications are linked to maternal reproductive tract dysbiosis originating from asymptomatic infections, such as chronic endometritis, probably arising prior to conception (4).

Dysbiosis, or change in the microbiome may result from numerous physiological and pathological states. Since ages it has been believed that female genital tract is inhabited predominantly by Lactobacilli which prevent infections, and pathologic changes in their profile may make the vagina susceptible to infections which may lead to preterm birth and pregnancy complications. The microbiome may also change with environment, weight, diet pattern and hormonal mileu. Thus, immunological, endocrinological and metabolic changes during pregnancy can cause significant alterations in the microbiome (5). 
Most of the earlier knowledge about the vaginal microbiome was derived from studies performing microscopic examination (wet mount and Gram stain) and cultures of swabs collected from the female genital tract. The advent of culture independent techniques like gene amplification and DNA- sequencing techniques have revolutionized metagenomics which can identify the host genome with the inhabiting micro-organisms in the female genital microbiome $(6,7)$. Traditional Sanger sequencing allowed sampling of the principal species present within a microbiome. Using Next-generation sequencing (NGS) and whole- genome sequencing, it is now feasible to obtain detailed analysis of microbial species present within any site in the body by simultaneous analysis of thousands of sequences (8). This has revolutionized microbiomics and helps in better understanding of eubiosis, which is a healthy balance of the vaginal microbiome, and to determine the various conditions under which the microbiome may be beneficial, are safely tolerated or may be associated with an adverse outcome.

\section{ALTERATION OF THE MICROBIOME DURING PREGNANCY}

Vaginal epithelial mucosa with tight junctions, cervix and thicker cervical mucus plug act as a physiological barrier against invasion of the intrauterine compartment by microorganisms during pregnancy. Throughout the reproductive career, the healthy bacteria and microbiota, predominantly, Lactobacillus spp., help in maintenance of a stable vaginal equilibrium and prevent infective states in the healthy reproductive tract. The continued balance of this microbiome during pregnancy aids to the intricate process of sustaining the pregnancy to an adequate gestational age. Despite this, the vaginal microbiome undergoes significant changes during pregnancy by increased stability, a decrease in overall diversity, and predominance of Lactobacillus species (8). The vaginal microbiome is quite stable with only shifts of the subtype of Lactobacillus and this offers resilience and protection in pregnancy (6). Abundance of Lactobacilli in pregnancy results in reduction of vaginal $\mathrm{pH}$ and an increased vaginal gland secretions which act as a barrier against pathogenic microbes (9). The major changes in the vaginal microbiome occur during early pregnancy, while during later stages of pregnancy and the puerperium, the vaginal microbiome gets back to baseline, with an increase in diversity, decrease in Lactobacilli, and enrichment of bacterial associates (10).

Complex changes in the maternal immune system during pregnancy protect the fetus and mother from infection by promoting development of fetal immunity and preventing fetal rejection by the mother. The genital tract microbiome modulates this immune behavior, however, it is also affected by these immune changes. The interaction between various microbial species and maternal immune system during pregnancy results in an overall increased tolerance to microorganisms. This is mediated by upregulating anti-inflammatory cytokines, initiation of endotoxin tolerance, and suppression of autophagy leading to down modulation of immune response (5). Any alteration in the vaginal microbiota may lead to an increase in pro-inflammatory cytokines with induction of inflammatory cascade and preterm labor. Although infections play a definite role in preterm birth, microbes have also been isolated form gestational tissues of women with normal pregnancy outcomes (11).

The hormonal changes during pregnancy (rising progesterone and estrogen levels) lead to numerous physiological effects which may affect the microbiome composition. In addition, the microbiome can also secrete hormones, highlighting the bidirectional nature of this interplay. However, the direct effects of progesterone and estrogen on the microbiota are not definitely proven (12).

Metabolic changes during pregnancy include changes in energy homeostasis, storage of fat, and hormonal profiles leading to elevated fasting blood sugar levels, insulin resistance, glucose intolerance and weight gain (13). Microbiota is also influenced by changes in metabolism, as noted in obesity, metabolic syndrome, and diabetes. Thus, the metabolic changes occuring in pregnancy are expected to influence the composition of microbiota.

\section{COMPOSITION OF THE VAGINAL MICROBIOTA}

The vaginal microbiota is a complex interplay of host cells, symbionts, pathogens with mucosal, endocrinological and immunological factors; and hence it keeps changing throughout a women's life cycle. During childhood, due to low estrogen and thin mucosa, it is mostly dominated by Gram-negative anaerobic bacteria (Bacteroides, Veillonella, Fusobacterium), Grampositive anaerobic bacteri (Peptococcus, Peptostreptococcus Actinomyces, Bifidobacterium and Propionibacterium) and certain aerobic bacteria (Staphylococcus aureus, S. epidermidis Streptococcus viridans, and Enterococcus faecalis) (14). The vaginal microbiome of prepubertal girls is characterized by less abundance of Lactobacilli, Gardnerella vaginalis, and Prevotella (15). Under the estrogenic effect of puberty, the vaginal epithelium thickens and becomes suitable for glucose-fermenting micro-organisms, hence the microbiome in puberty resembles that of adult women being dominated by Lactobacillus spp. Other inhabitants include Escherichia, Staphylococcus, Corynebacterium, Gardnerella, Streptococcus, Mycoplasma, Mobiluncus, Prevotella, and Atopobium (16). Lactic acid produced by Lactobacilli acidifies the vaginal $\mathrm{pH}$ $(<4.5)$ thus creating a hostile environment for colonization of pathogenic bacteria and fungi (17). Molecular diagnostic techniques have enabled detection of uncultivated bacteria that were earlier missed by conventional culture techniques. On the basis of the composition of bacterial species in reproductive age women, certain unique microbial community types have also been identified.

As the estrogen levels decline at menopause, the microbiome begins to be composed predominantly by Lactobacillus crispatus, L. iners, G. vaginalis, and Prevotella with a less proportion of Candida, Staphylococcus, Mobiluncus and Bifidobacterium and hence the vaginal microbiome starts resemblimg pre-pubertal girls (18). 
During pregnancy, the presence of normal microbiota helps to protect the genital tract against infection. The vaginal microbiomal patterns of pregnant women delivering at term gestation is different from those of non-pregnant women. Romero et al. (19) used 16sRNA gene sequencing and demonstrated that vaginal microbiome of pregnancy shows more stability than in the non-pregnant state with greater abundance of L. vaginalis, L. crispatus, L. gasseri, and L. jensenii. Aagard et al. used NGS to study the changes in vaginal microbiome during pregnancy and found that microbial community varies with gestation and proximity to cervix (8). Freitas et al. also studied the vaginal microbiomes of pregnant women and found less diversity and richness with lesser Mycoplasma and Ureaplasma loads, Lactobacilli abundance and higher bacterial concentration as compared to non-pregnant ones (20). Recent studies have used techniques like RNA gene sequencing to compare the vaginal microbiome of women with Preterm birth (PTB) with those delivering at term and have revealed higher microbial richness and diversity with decreased Lactobacilli, abundance of Gardnerella and other organisms causing BV (21). Recently, 16srRNA gene taxonomic analysis, cytokine profiling and bacterial genome analysis have been utilized to investigate the dynamics of pregnancy microbiome and specific signature microbiomes have been identified in women with PTB (22).

An alteration in microbiome composition also called dysbiosis, may make a woman susceptible to genital tract infections which can result in adverse gestational outcomes like preterm onset of labor, preterm prelabour rupture of membranes (pPROM), pre-eclampsia, miscarriage, fetal growth restriction, low birth weight, stillbirth, and neonatal sepsis (23). These infections may ascend from the vagina or cervix or may be seeded haematogenously from non-genital sources like periodontal infections (24-27). Figure 1 highlights the changes in vaginal microbiome with the causative factors and implications of the change.

\section{MYCOBIOME AND VIROME}

Researchers have traditionally focussed mainly on the bacteriological aspect of the vaginal microbiome. However, viruses and fungi also contribute to the microbiome and the metagenomics. Hence, authors have termed this as the 'Mycobiome' and 'virome' (28). Zheng et al. have studied the vaginal mycobiome and found Candida and Saccharomyces as the predominant species with alterations in the mycobiome with diabetes and pregnancy (29). The vaginal virome has been poorly identified due to difficulties in isolation owing to small viral genomic material and ongoing mutations. However, Herpesviridae, Papillomaviridae, Polomaviridae and Parvoviridae have been isolated (30).

\section{OTHER GENITAL MICROBIOTA}

The vaginal microbiota is the most comprehensively studied microbiome with significant changes in pregnancy and associated with adverse pregnancy outcomes in dysbiotic states. The cervix also has its distinct microbiome. While the ectocervix has stratified epithelial cells resembling the vagina, the pattern of microbiome is also similar and heavily laden; often called cervico-vaginal microbiome. Presence of mucins in the cervical mucus offer antimicrobial activity to prevent ascending infections to the upper genital tract. The endocervix is lined by a single layer of columnar cells with cell junctions and is generally considered sterile, though this has been challenged by identification of microbes using NGS. Distinct microbiota have also been isolated from the endometrium, ovaries and fallopian tubes $(30,31)$. The association of these microbiota have been studied in women undergoing assisted reproductive techniques. The endometrium has a unique microbiome comprising Bacteriodetes esp Flavobacterium spp. and Firmicutes (Lactobacillus spp) (30, 31). Ovarian follicular fluid and fallopian tubes have shown presence of Propionibacterium, Streptococcus and Lactobacillus. Alteration in these microbiomes have been associated with recurrent implantation failures (31)

\section{DYSBIOSIS AND ADVERSE PREGNANCY OUTCOME}

The cause of spontaneous PTB is often unknown, but intrauterine infection is consistently implicated in upto $40 \%$ of cases (28). Predisposing factors for infection-related PTB are include intra-amniotic infections, sub-clinical infections and periodontal infections $(5,25,26)$. Infections which may cause PTB usually begin in the lower genitourinary tract, ascend upwards and possibly cross the placental barrier. Studies have linked amniotic fluid infection and PTB, postulating that the presence of bacteria within the amniotic cavity is pathological (32). However, other studies have also isolated bacteria from the amniotic cavities of women with term pregnancies (33). Bacteria inhabiting the oral cavity have been also found in amniotic fluid and the placenta without any overt or concomitant inflammation (34). Therefore, their direct causative link is debatable. Infection may occur before conception or early in pregnancy and may also be asymptomatic and undetected (35).

Potential sites of infection include the amniotic cavity with fluid and amniotic membranes, umbilical cord and placenta. Many bacteria have been isolated in such infective states associated with PTB; most common being Ureaplasma, Mycoplasma, Bacteroides spp., Gardnerella vaginalis, and Fusobacterium (35). These infections implicated in PTB are associated with organisms with low virulence and early vulnerability in early pregnancy leading to chronic intrauterine infections in the absence of overt clinical signs of infection (5). But, once within the uterine cavity, they induce the release of pro-inflammatory cytokines, prostaglandins, and metalloproteases. These can trigger cervical ripening and shortening, weakening of membranes and rupture, uterine contractility, and PPROM or PTB $(5,28,30)$. 
- Thicker vaginal epithelium with tight junctions and increased glycogen

- Cervical mucus plug: Abundant and thicker mucus

- Changes in maternal immune system

- Changes in hormonal mileu

- Metabolic changes

CAUSATIVE FACTORS

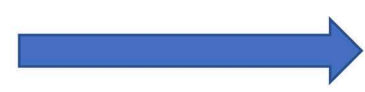

Pregnancy microbiome

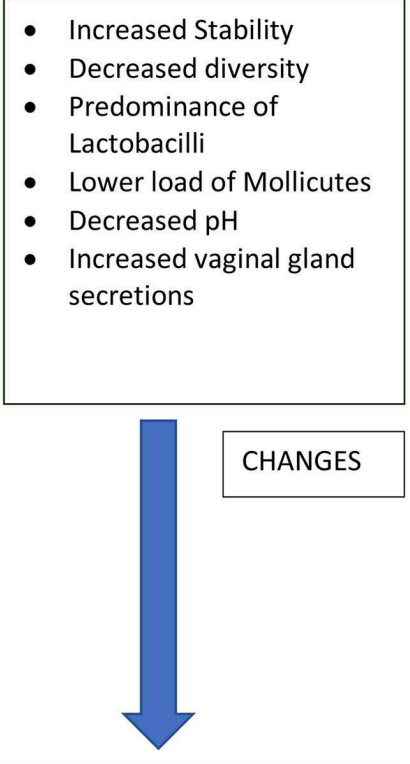

- Miscarriages

- Preterm labour

- pPROM

- Pre-eclampsia

- Fetal growth restriction

- Low birth weight

- Post abortal/post partum sepsis

- Neonatal sepsis \& associated morbities

EFFECTS OF DYSBIOSIS

FIGURE 1 | Changes in vaginal microbiome in pregnancy.

\section{DYSBIOSIS AND ADVERSE NEONATAL OUTCOMES}

Evidence suggest that maternal microbiome acts a bacterial reservoir for microbial seeding of the newborn (36). Studies have evaluated the microbiota of newborn babies delivering vaginally and compared with those born through cesarean section and have found differences. Vaginally delivered infants harbor bacteria resembling the maternal vaginal microbiome, whereas the microbiome of cesarean delivered babies are similar to the microbiota of maternal skin (37). The transmission of vaginal microbiota to the infant may have a protective effect by reduction of Methicillin Resistant Staphylococcus Aureus (MRSA) colonization and also by other possible microbes as these site-specific microbial communities develop. Recent evidence also reveal that initial exposure to a specific type of maternal microbiome may influence successive microbial patterns in the gut and other body environments and can influence infant outcomes positively or negatively $(38,39)$. Microbes in the amniotic-cavity trigger an inflammatory response which makes neonates susceptible to both short-term and long- term consequences, such as early-onset neonatal sepsis (EONS), bronchopulmonary dysplasia, and cerebral palsy $(40,41)$.

\section{AMNIOTIC FLUID MICROBIOTA}

The microbial pattern in amniotic fluid is characterized by less abundance and low richness and diversity. With the advent of PCR techniques, micro-organisms have also been isolated from sterile amniotic cavities (6). Species commonly isolated are Proteobacteria, Enterobacteriaceae (Enterobacter, Escherichia, Shigella) (31, 42). Species of Lactobacillus, Propionibacterium, Staphylococcus, and Streptococcus have also been detected in amniotic fluids and in the placentae (31). Infant gut microbiological colonization possibly starts in utero as microbial species in the meconium is dominated by Streptococcus, Enterobacteriaceae (mostly Enterobacter and Escherichia), Lactobacillus, and Propionibacterium and exhibits similarity 
with the amniotic fluid and placental microbiome (43). Microbiological colonization of the uterus, amniotic fluid and placenta allows the fetus to exhibit tolerance to bacteria after birth through the phenomenon of priming as it affects the innate gene expression of immune reaction in the fetus and establishment of a healthy microbiome in the newborn $(31,43)$.

\section{PLACENTAL MICROBIOTA}

Both culture and metagenomic techniques have now exhibited the presence of bacteria in the healthy placentae as well (44). Bacteria have also been isolated from placentas of healthy women without chorioamnionitis (45). The presence of placental microbial colonization in a majority of women without apparent adverse perinatal outcomes reinforces that the placental microbiome may be advantageous $(33,46)$. Wholegenome sequencing has reported that the placenta contains a unique microbiome, somewhat similar to the oral one and not the vaginal microbiome $(8,27)$. This similarity between the placental microbiota and oral microbiota may be because periodontal infections have also been linked with an increased incidence of pregnancy complications (25-27). It is postulated that bacteria may transmit from the oral cavity to placenta possibly by hematogenous route and not by the ascending migration from lower genital tract. Other studies, however, doubt the presence of a placental microbiome, because bacterial colonization is of low biomass and therefore may be just a contamination (47). Most common isolates from the placental microbiome are Protobacteria, Bacteroides, Fusobacteria and Tenericutes (31).

Placental colonization if associated with histological evidences of placental inflammation is associated with likelihood to develop pathological effects in neonates like retinopathy or EONS $(48,49)$.

\section{COMMON GENITAL INFECTIONS IN PREGNANCY}

Normal vaginal microbiome comprises of both aerobic and anaerobic bacteria, with Lactobacillus being amongst the predominant microbiota. Lactobacilli provide defense against infections by maintainence of an acidic vaginal $\mathrm{pH}$ and ensuring the presence hydrogen peroxide. Decreased concentration of lactobacillus with a concomitant increase in pathogenic microbes may alter the genital tract microbiome and may lead to various infections resulting due to dysbiotic states. Genital infective states often remain inconspicuous during pregnancy, as their signs and symptoms are overlooked as normal symptoms of pregnancy. Additionally, reluctancy to take treatment and reduced tolerability in pregnancy increases the incidence of under-treatment and recurrences. Infections like Vulvovaginal candidiasis (VVC), BV (Bacterial vaginosis), TV (Trichomonas vaginalis), HPV (Human Papilloma Virus), HIV(Human Immunodeficiency Virus), HSV(Herpes Simplex Virus), Neisseria gonorrhoeae, Chlamydia trachomatis etc may be consequent to dysbiotic states. HPV is one such infection which infects the basal layer of cervical epithelium and is now believed to be linked to alterations in the vaginal microbiome. Severity of epithelial lesions and progression to cancer has also been associated with certain microbiome patterns due to added oxidative damage and nitrosamines by the microbes (30).

The most commonly encountered dysbiotic conditions during pregnancy namely VVC, BV and TV will be highlighted here.

\section{Vulvovaginal Candidiasis in Pregnancy}

Vulvovaginal candidiasis is a frequent dysbiosis affecting upto $75 \%$ of women at least once in their lifetime and $40-45 \%$ will have two or more episodes (50). Risk factors include recent sexual activity, antibiotic intake, pregnancy, and immunosuppressive states resulting from conditions such as HIV or diabetes. The risk for developing VVC among healthy women is $\sim 20 \%$, it increases by $30 \%$ during the last trimester of pregnancy (51). VVC is caused mainly by Candida albicans; however, other species of Candida such as C.glabrata, C.parapsilosis, and C.tropicalis may be implicated. Candida colonization may disrupt normal microbiome leading to reduction in lactobacilli and an increased pathogenic organisms. Symptoms of candidiasis include nonoffensive vaginal discharge, vulval itch, soreness or dysparunea.

In pregnancy, VVC may often be prolonged and associated with more severity in symptoms requiring longer courses of treatment for resolution of symptoms. Although pregnant women are more frequently infected by VVC, they appear to be less symptomatic for vulvovaginitis (52). Topical azoles remain the first line of treatment for vulvovaginal candidiasis during pregnancy (53). Topical Imidazole and vaginal ovules may be used for 2 weeks with repeat courses, if indicated. Oral Fluconazole is avoided in pregnancy as it is reported to be associated with risk of Tetralogy of Fallot, miscarriages and still birth (54-56). Topical imidazoles are safe and effective for the VVC in pregnancy and in breastfeeding as well. Fluconazole levels in breast milk are very low and unlikely to cause harm. Breastfeeding can be continued after a single dose of $150 \mathrm{mg}$ Fluconazole but may be avoided after high doses or repeated courses of fluconazole (57). There is lack of data to evaluate the efficacy of long-term maintenance doses of oral azoles for treating recurrent VVC in pregnancy. Suppressive therapy in pregnancy is generally not offered; thus treating individual episodes with a topical imidazole kept vaginally for 1 week.

The incidence of ascending candidial infection is about $0.8 \%(58,59)$. C. albicans needs hyphae formation for local invasion and for crossing intact fetal membranes. It may enter amniotic cavity from the intervillous space or through upward ascent. Chorioamnionitis is rarely linked with VVC in pregnancy or in the presence of foreign bodies such as intrauterine devices or encerclage, and prolonged membrane rupture (59, $60)$. The mechanism by which VVC during pregnancy may lead to preterm birth remains speculative. Possible release of candidal aspartyl proteinases combined with other virulence factors may promote the degradation of the cervical plug; hence facilitating bacterial ascent in the gravid uterus. There is inconclusive evidence to link the association between VVC and premature delivery or low birth weight $(58,60)$. Similarly data 
to recommend treatment of asymptomatic candidial infection in pregnancy to reduce preterm birth is also inconclusive (60).

There is inconclusive evidence to advocate the use of probiotics as an adjuvant therapy in candidiasis in women. It can increase the clinical and mycological cure for a short period and reduce the 1 month- relapse rate at but is ineffective for longterm clinical or mycological cure (61). The same effect cannot be extrapolated to pregnant women and its use is not justified.

\section{Bacterial Vaginosis in Pregnancy}

It is the most common cause of lower genital tract infection in both pregnant and non-pregnant women (62). Bacterial vaginosis is a dysbiotic state in which the vaginal microbiome that is dominated by Lactobacilli is replaced by an overgrowth of certain anaerobic and facultative bacteria. Majority of the women with such an altered microbiome do not elicit any signs or symptoms apart from elevated vaginal $\mathrm{pH}$ and microscopic presence of Clue cells studded with bacteria. It may be diagnosed using the clinical Amsel's criteria or Gram staining. Use of PCR and culture techniques for diagnosis is under research settings only. Symptomatic women have a thin milky white foul smelling vaginal discharge. There is no single microorganism implicated in the diagnosis of $\mathrm{BV}$, but rather the alteration of microbiome and presence of different bacteria which characterize this. The bacterial composition of $\mathrm{BV}$ include $G$. vaginalis, Mycoplasma, Atopobium vaginalis, and species of Clostridiales, Mobilincus, Prevotella, and Leptotrichia, but may vary with ethnic groups (58). Bacterial vaginosis may lead to increased susceptibility to STIs and complications after gynecological surgeries. BV during pregnancy has been associated with different obstetric complications such as preterm labor and PTB, pPROM, spontaneous miscarriages, chorioamnionitis, pueperial sepsis, Cesarean wound infections, and gynaecologic complications like postoperative infections and subclinical pelvic inflammatory disease (63-66).

How BV increases susceptibility to adverse pregnancy outcome remains to be confirmed. One hypothesis is that bacteria in the altered microbiome release proteases especially Matrix metalloproteinase- 8 , sialidases, and other enzymes that disrupt the integrity of the cervical plug $(67,68)$ their high bacterial concentration in the vagina in $\mathrm{BV}$, leads to possible migration of bacteria into the upper reproductive tract. There, induction of inflammatory cytokines interferes promotes the induction of preterm labor.

Vaginal discharge is commonly reported in pregnancy and may be physiological as well. Women with persisting discharge may be screened for the presence of genital infections. If bacterial vaginosis is detected in a symptomatic pregnant woman, treatment is indicated.

Women with asymptomatic BV are not at risk for pregnancy complications; but those with associated infections or risks of prematurity risks possibly are. Occurrence of BV and its implicated flora are not deleterious per se: the interaction with the host, causing an inflammatory reaction, may be implicated for its effects. CDC recommends both oral and topical regimes for treating symptomatic bacterial vaginosis in pregnancy: Metronidazole $500 \mathrm{mg}$ twice daily for 7 days or metronidazole gel $(0.75 \%, 5 \mathrm{~g}$ applicator) vaginally for 5 days or clindamycin cream $(2 \%, 5 \mathrm{~g}$ applicator) intravaginally for 1 week. Alternate regimes include oral clindamycin $300 \mathrm{mg}$ twice daily for 1 week or clindamycin ovules $100 \mathrm{mg}$ vaginally for 3 nights (69). Both metronidazole and clindamycin eradicate upto $85 \%$ of $\mathrm{BV}$, but recurrences up to $40-80 \%$ are common (70). High recurrence rate may be reduced by follow-up examinations during pregnancy. Likelihood of relapses are not affected by treatment of sex partners (69). Earlier studies had raised concern about metronidazole use in pregnancy but recent evidences by meta analysis have not found any association with metronidazole and teratogenicity or mutagenic effects in newborns. Although metronidazole crosses the placenta, the plasma levels in the neonate are less (71). Few clinicians advise deferring breastfeeding for $12 \mathrm{~h}$ only after maternal therapy with ( $2 \mathrm{~g}$ ) single dose metronidazole, not with the lower doses. Vaginal clindamycin has also been reported to be safe in pregnancy. Tinidazole should be avoided (69).

Although adverse pregnancy outcomes like PTB, chorioamnionitis, and puerperal endometritis have been linked with BV in few studies, there has been conflicting evidence till date. A recent meta-analysis reported that antibiotic therapy regime could not prevent preterm birth in women with BV (symptomatic or asymptomatic) (72).

Treatment of asymptomatic BV infection in pregnancy in women with risk of preterm delivery (e.g., previous preterm birth) has yielded inconclusive results in studies. (69). A recent review showed a lower preterm birth rate if $\mathrm{BV}$ was treated with clindamycin, especially before 22 weeks in women at risk of infection-related preterm birth (73). Similarly, treatment of asymptomatic BV in pregnant women with low risk of PTB is controversial. One study revealed $40 \%$ reduction in PTB amongst women using clindamycin between gestation weeks 13-22 $(74,75)$. Others studies have shown no benefit (76). Therefore, routine screening and treatment of BV in asymptomatic pregnant women at high or low risk for PTB is not recommended (69).

Recent evidences have explored the use of probiotics for the treatment of isolated episodes and recurrent BV. Unfortunately, there is lack of evidence to promote the usage of these agents. One study from China has reported lower recurrence rates in women with recurrent BV using daily vaginal probiotic use compared to placebo (77). Another recent analysis found no harm in administering probiotics (78). A recent trial has shown that that intermittent use of intermittent use of lactobacilli-containing vaginal probiotics may reduce recurrence of $\mathrm{BV}$ and may be preferred by both clinicians as they do not affect other body microbiomes or lead to antibiotic resistance (79). Recently, few authors have also reported successful usage of vaginal microbiome transplantation from healthy donors as an alternative for patients with symptomatic, recurrent and intractable BV $(80,81)$. However, lack of prudent data makes it difficult to extrapolate such treatment modalities in pregnant women. 


\section{Trichomonas Vaginitis (TV) in Pregnancy}

Trichomonas Vaginitis is one of the commonest non-viral sexually transmitted infections world-wide. In the absence of true surveillance programs, the epidemiology of TV is not completely studied. It, however, shows variations with ethnic populations and geography. Majority of the women (85\%) infected with TV are asymptomatic (82). Symptomatic women complain of diffuse vaginal discharge which is commonly malodorous, yellow-green, associated with dysuria, itching, vulvar irritation and pelvic pain. TV in pregnancy may been associated with PTB and low birth weight (83).

If a woman is symptomatic and tested to have TV infection, treatment is indicated. TV Screening in women with a history of PTB or pPROM is controversial and so is treatment for asymptomatic infection in such cases. Routine screening and treatment of asymptomatic pregnant women with no prior history is not recommended. Some studies have shown benefit with parasitological cure, while few have shown higher rates of PTB in the treated group (84-87).

Metronidazole is considered safe in pregnancy and various meta-analyses have not shown any higher risk of teratogenicity $(88,89)$. The recommended dose of metronidazole in pregnancy is similar to that for non-pregnant women $(2 \mathrm{~g})(86,90)$. Tinidazole has not been comprehensively studied in pregnancy and remains a class $\mathrm{C}$ drug. Lactation should be withheld in women who are administered metronidazole for $12-24 \mathrm{~h}$ after the last dose and for 3 days after the last intake of tinidazole to reduce the exposure to the infant (90).

Treatment of $T$. vaginalis infection can provide symptomatic relief in pregnant women and mitigate the sexual transmission to partners, although recurrences are high (91). Although perinatal transmission of trichomoniasis is rare, maternal antibiotics also prevents respiratory and genital infection of the infant (92).

\section{REFERENCES}

1. Ansbacher R, Boyson WA, Morris JA. Sterility of the uterine cavity. Am J Obstet Gynecol. (1967) 99:394-6. doi: 10.1016/S0002-9378(16) 34549-5

2. Steel JH, Malatos S, Kennea N, Edwards AD, Miles L, Duggan P, et al. Bacteria and inflammatory cells in fetal membranes do not always cause preterm labor. Pediatr Res. (2005) 57:404-11. doi: 10.1203/01.PDR.0000153869.96 337.90

3. Toth M, Witkin SS, Ledger WJ, Thaler H. The role of infection in the etiology of preterm birth. Obstet Gynecol. (1988) 71:723-6.

4. Ravel J, Brotman RM. Translating the vaginal microbiome: gaps and challenges. Genome Med. (2016) 8:35. doi: 10.1186/s13073-016-0291-2

5. Ramos BA, Kanninen TT, Sisti G, Witkin, SS. Microorganisms in the female genital tract during pregnancy: tolerance versus pathogenesis. Am. J. Reprod. Immunol. (2015) 73:383-9. doi: 10.1111/aji.12326

6. Solt I. The human microbiome and the great obstetrical syndromes: a new frontier in maternal-fetal medicine. Best Pract Res Clin Obstet Gynaecol. (2015) 29:165-75. doi: 10.1016/j.bpobgyn.2014.04.024

7. Romero R, Miranda J, Chaiworapongsa T, Chaemsaithong P, Gotsch F, Dong $\mathrm{Z}$, et al. A novel molecular microbiologic technique for the rapid diagnosis of microbial invasion of the amniotic cavity and intra- amniotic infection in preterm labor with intact membranes. Am J Reprod Immunol. (2014) 71:330-58. doi: 10.1111/aji.12189

\section{Alternate Therapy}

There is promising evidence from recent studies promoting the use of vaginal microbicidal creams and poly-herbal pessaries in non- pregnant women with vaginal infections $(93,94)$. Vaginal microbicides help to minimize the mucosal trauma and have minimal adverse effects. Effectiveness of such agents needs to be evaluated in pregnant women. Recent reports have also highlighted the use of vaginal microbiomal transplantation in refractory and recurrent cases of vaginal infections $(80,81)$.

\section{Summary}

Microbial colonization of reproductive tract during pregnancy is common and may not always result in complications. Alteration in genital microbiota during pregnancy may involve interactions between infectious agent and the maternal immunity and may lead to inflammatory response and consequent adverse pregnancy outcomes. Women at risk of adverse perinatal outcomes should be timely screened and appropriately treated. Specific interactions between various microorganisms and host mechanisms that promote symbiosis or pathology needs to further evaluated. With the advent of metagenomics and NGS, it may soon be plausible in the future. This may lead to early detection and cure of dysbiotic states with targeted therapies to improve pregnancy outcomes. While antimicrobial therapy has been extensively studied for the cure of vaginal dysbiotic states, novel therapy like probiotics, microbicides and microbiome transplantation appear promising.

\section{AUTHOR CONTRIBUTIONS}

RB: framework, draft, and correction. PA: draft, correction, and review. All authors contributed to the article and approved the submitted version.

8. Aagaard K, Riehle K, Ma J, Segata N, Mistretta TA, Coarfa $\mathrm{C}$, et al. A metagenomic approach to characterization of the vaginal microbiome signature in pregnancy. PLoS ONE. (2012) 7:e36466. doi: 10.1371/journal.pone.0036466

9. Prince AL, Antony KM, Ma J, Aagaard KM. The microbiome and development: a moth- er's perspective. Semin Reprod Med. (2014) 32:1422. doi: 10.1055/s-0033-1361818

10. MacIntyre DA, Chandiramani M, Lee YS, Kindinger L, Smith A, Angelopoulos $\mathrm{N}$, et al. The vaginal microbiome during pregnancy and the postpartum period in a European population. Sci Rep. (2015) 5:8988. doi: 10.1038/srep08988

11. Nuriel-Ohayon $M$, Neuman $H$ Koren O. Microbial changes during pregnancy, birth, and infancy. Front Microbiol. (2016) 7:1031. doi: 10.3389/fmicb.2016.01031

12. Wira CR, Fahey JV, Rodriguez-Garcia M, Shen Z, Patel MV. Regulation of mucosal immunity in the female reproductive tract: the role of sex hormones in immune protection against sexually transmitted pathogens. Am. J. Reprod. Immunol. (2014) 72:236-58. doi: 10.1111/aji.12252

13. Isolauri E, Sherman PM, Walker WA, editors. Intestinal microbiome: functional aspects in health and disease. Nestlé Nutr Inst Workshop Ser. (2017) 88:1-9. doi: 10.1159/isbn.978-3-318-06031-7

14. Randelovic G, Mladenović V, Ristić L, Otašević S, Branković S, MladenovićAntić S, et al. Microbiological aspects of vulvo-vaginitis in prepubertal girls. Eur J Pediatr. (2012) 171:1203-8. doi: 10.1007/s00431-012-1705-9 
15. Yamamoto T, Zhou X, Williams CJ, Hochwalt A, Forney LJ. Bacterial populations in the vaginas of healthy adolescent women. J Pediatr Adolesc Gynecol. (2009) 22:11-8. doi: 10.1016/j.jpag.2008.01.073

16. Pietrzak B. Biocenosis the vagina in a variety of periods of a woman's life. In: Wielgos M, Gdansk VM, editors. Vaginal Infections. Gdansk: VM Media (2013). p. 1-5

17. O'Hanlon DE, Moench TR, Cone RA. Vaginal $\mathrm{pH}$ and microbicidal lactic acid when lactobacilli dominate the microbiota. PLOS ONE. (2013) 8:e80074. doi: 10.1371/journal.pone.0080074

18. Hickey RJ, Zhou X, Settles M, Erb J, Malone K, Hansmann MA et al. Vaginal microbiota of adolescent girls prior to the onset of menarche resemble those of reproductive-age women. mBio. (2015) 6:e0009715. doi: 10.1128/mBio.00097-15

19. Romero R, Hassan SS, Gajer P, Tarca AL, Fadrosh DW, Nikita L, et al. The composition and stability of the vaginal microbiota of normal pregnant women is different from that of non-pregnant women. Microbiome. (2014) 2:4. doi: 10.1186/2049-2618-2-10

20. Freitas, AC, Chaban B, Bocking A, Rocco M, Yang S, Hill JE, et al. The vaginal microbiome of pregnant women is less rich and diverse, with lower prevalence of Mollicutes, compared to non-pregnant women. Sci Rep. (2017) 7:9212. doi: 10.1038/s41598-017-07790-9

21. Hočevar K, Maver A, Vidmar Šimic M, Hodžić A, Haslberger A, Premru Seršen T, et al. Vaginal microbiome signature is associated with spontaneous preterm delivery. Front Med. (2019) 6:201. doi: 10.3389/fmed.2019. 00201

22. Fettweis JM, Serrano MG, Brooks JP, Edwards DJ, Girerd PH, Parikh HI, et al. The vaginal microbiome and preterm birth. Nat. Med. (2019) 25:101221. doi: 10.1038/s41591-019-0450-2

23. Romero R, Hassan SS, Gajer P, Tarca AL, Fadrosh DW, Bieda J, et al. The vaginal microbiota of pregnant women who subsequently have spontaneous preterm labor and delivery and those with a normal delivery at term. Microbiome. (2014) 2:18. doi: 10.1186/2049-2618-2-18

24. Mysorekar IU, Cao B. Microbiome in parturition and preterm birth. Semin Reprod Med. (2014) 32:50-5. doi: 10.1055/s-0033-1361830

25. Wang YL, Liou JD, Pan WL. Association between maternal periodontal disease and preterm delivery and low birth weight. Taiwan J Obstet Gynecol. (2013) 52:71-6. doi: 10.1016/j.tjog.2013.01.011

26. Mariano Sanz, Kenneth Kornman, Working group 3 of the joint EFP/AAP workshop. Periodontitis and adverse pregnancy outcomes: consensus report of the joint EFP/AAP workshop on periodontitis and systemic diseases. J Periodontol. (2013) 84 (Suppl. 4):S164-9. doi: 10.1902/jop.2013. 1340016

27. Hongyu Ren, Minquan Du. Role of maternal periodontitis in preterm birth. Front Immunol. (2017) 8:139. doi: 10.3389/fimmu.2017.00139

28. Goldenberg RL, Hauth JC, Andrews WW. Intrauterine infection and preterm delivery. $N$ Engl J Med. (2000) 342:15007. doi: 10.1056/NEJM200005183422007

29. Zheng NN, Guo XC, Lv W, Chen XX, Feng GF. Characterization of the vaginal fungal flora in pregnant diabetic women by $18 \mathrm{~S} r$ RNA sequencing. Eur J Clin Microbiol Infect Dis. (2013) 32:1031-40. doi: 10.1007/s10096-013-1847-3

30. Kaminska D, Gajecka $M$. Is the role of human female reproductive tract microbiota underestimated? Beneficial Microbes. (2017) 8:327-43 doi: 10.3920/BM2015.0174

31. Younes JA, Lievens E, Hummelen R, van der Westen R, Reid G, Petrova MI. Women and their microbes: the unexpected friendship. Trends Microbiol. (2017) 26:16-32. doi: 10.1016/j.tim.2017.07.008

32. Han YW, Shen T, Chung P, Buhimschi IA, Buhimschi CC. Uncultivated bacteria as etiologic agents of intra-amniotic inflammation leading to preterm birth. J Clin Microbiol. (2009) 47:38-47. doi: 10.1128/JCM.01206-08

33. Parnell LA, Briggs CM, Cao B, Delannoy-Bruno O, Schrieffer AE, Mysorekar IU. Microbial communities in placentas from term normal pregnancy exhibit spatially variable profiles. Sci Rep. (2017) 7:11200. doi: 10.1038/s41598-017-11514-4

34. Madianos PN, Bobetsis YA, Offenbacher S. Adverse pregnancy outcomes (APOs) and periodontal disease: pathogenic mechanisms. I Periodontol. (2013)84:S170-80 doi: 10.1902/jop.2013.1340015

35. Combs CA, Gravett M, Garite TJ, Hickok DE, Lapidus J, Porreco R et al. Amniotic fluid infection, inflammation, and colonization in preterm labor with intact membranes. Am J Obstet Gynecol. (2014) 210:125.e1125.e15. doi: 10.1016/j.ajog.2013.11.032

36. Mueller NT, Bakacs E, Combellick J, Grigoryan Z, Dominguez-Bello MG. The infant microbiome development: mom matters. Trends Mol. Med. (2015) 21:109-17. doi: 10.1016/j.molmed.2014.12.002

37. Dominguez-Bello MG, Costello EK, Contreras M, Magris M, Hidalgo $\mathrm{G}$, Fierer $\mathrm{N}$, et al. Delivery mode shapes the acquisition structure of the initial microbiota across multiple body habitats in newborns. Proc Natl Acad Sci USA. (2010) 107:11971-5. doi: 10.1073/pnas.1002 601107

38. Gomez de Aguero M, Ganal-Vonarburg SC, Fuhrer T, Rupp S, Uchimura $\mathrm{Y}, \mathrm{Li} \mathrm{H}$, et al. The maternal microbiota drives early postnatal innate immune development. Science. (2016) 351:1296-302. doi: 10.1126/science. aad2571

39. Adlerberth I, Lindberg E, Åberg N, Hesselmar B, Saalman R, Strannegård IL, et al. Reduced enterobacterial and increased staphylococcal colonization of the infantile bowel: an effect of hygienic lifestyle? Pediatr Res. (2006) 59:96-101. doi: 10.1203/01.pdr.0000191137.12774.b2

40. Kemp MW. Preterm birth, intrauterine infection, and fetal inflammation. Front Immunol. (2014) 5:574. doi: 10.3389/fimmu.2014.00574

41. Hodyl NA, Aboustate N, Bianco-Miotto T, Roberts CT, Clifton VL, Stark MJ. Child neurodevelopmental outcomes following preterm and term birth: what can the placenta tell us? Placenta. (2017) 57:7986. doi: 10.1016/j.placenta.2017.06.009

42. Mendz GL, Kaakoush NO, Quinlivan JA. Bacterial aetiological agents of intraamnioptic infections and preterm birth in pregnant women. Front Cell Infect Microbiol. (2013) 3s:58. doi: 10.3389/fcimb.2013.00058

43. Collado MC, Rautava S, Aakko J, Isolauri E, Salminen S. Human gut colonisation may be initiated in utero by distinct microbial communities in the placenta and amniotic fluid. Sci. Rep. (2016) 6:23129. doi: 10.1038/srep23129

44. Aagaard K, Ma J, Antony KM, Ganu R, Petrosino J, Versalovic J. The placenta harbors a unique microbiome. Sci Transl Med. (2014) 6:23765. doi: 10.1126/scitranslmed.3008599

45. Lauder AP, Roche AM, Sherrill-Mix S, Bailey A, Laughlin AL, Bittinger K, et al. Comparison of placenta samples with contamination controls does not provide evidence for a distinct placenta microbiota. Microbiome. (2014) 4:29. doi: 10.1186/s40168-016-0172-3

46. Leiby JS, McCormick K, Sherrill-Mix S, Clarke EL, Kessler LR, Taylor LJ, et al. Lack of detection of a human placenta microbiome in samples from preterm and term deliveries. Microbiome. (2018) 6:196. doi: 10.1186/s40168-018-0575-4

47. Zhu L, Luo F, Hu W, Han Y, Wang Y, Zheng H, et al. Bacterial communities in the womb during healthy pregnancy. Front Microbiol. (2018) 9:16. doi: $10.3389 /$ fmicb. 2018.02163

48. Chen ML, Allred EN, Hecht JL, Onderdonk A, VanderVeen D, Wallace DK, et al. Placenta microbiology and histology and the risk for severe retinopathy of prematurity. Invest Ophthalmol Vis Sci. (2011) 52:70528. doi: 10.1167/iovs.11-7380

49. Arora P, Bagga R, Kalra J, Kumar P, Radhika S, Gautam V. Mean gestation at delivery and histological chorioamnionitis correlates with early-onset neonatal sepsis following expectant management in pPROM. J Obstet Gynaecol. (2015) 35:235-40. doi: 10.3109/01443615.2014. 958143

50. Hurley R, De Louvois J. Candida vaginitis. Postgrad Med J. (1979) 55:64547. doi: 10.1136/pgmj. 55.647 .645

51. Gonçalves B, Ferreira C, Alves CT, Henriques M, Azeredo J, Silva S. Vulvovaginal candidiasis: epidemiology, microbiology and risk factors. Crit Rev Microbiol. (2015) 21:1-23. doi: 10.3109/1040841X.2015. 1091805

52. Aguin TJ, Sobel JD. Vulvovaginal candidiasis in pregnancy. Curr Infect Dis Rep. (2015) 17:30 doi: 10.1007/s11908-015-0462-0

53. Young G, Jewell D. Topical treatment for vaginal candidiasis (thrush) in pregnancy. Cochrane Database Syst Rev. (2001) 4:CD000225. doi: 10.1002/14651858.CD000225

54. Mølgaard-Nielsen D, Svanström H, Melbye M, Hviid A, Pasternak B. Association between use of oral fluconazole during pregnancy and risk of spontaneous abortion and stillbirth. JAMA. (2016) 315:5867. doi: $10.1001 /$ jama.2015.17844 
55. Howley MM, Carter TC, Browne ML, Romitti PA, Cunniff CM, Druschel CM. Fluconazole use and birth defects in the National Birth Defects Prevention Study. Am J Obstet Gynecol. (2016) 214:657.e1-657.e9 doi: 10.1016/j.ajog.2015.11.022

56. Bérard A, Odile S, Zhao JP, Gorgui J, Bernatshy S, Soares C, et al. Associations between low- and high-dose oral fluconazole and pregnancy outcomes: 3 nested case-control studies. CMAJ. (2018) 191:E179-87. doi: 10.1503/cmaj.180963

57. Bauters T, Dhont M, Temmerman M, I, Nelis H. Prevalence of vulvovaginal candidiasis and susceptibility to fluconazole in women. Am J Obstet Gynecol. (2002) 187:569-74. doi: 10.1067/mob.2002.125897

58. Cotch MF, Hillier SL, Gibbs RS, Eschenbach DA. Epidemiology and outcomes associated with moderate to heavy Candida colonisation during pregnancy. Am J Obstet Gynecol. (1998) 178:374-80. doi: 10.1016/S0002-9378(98) 80028-8

59. Meizoso T, Rivera T, Fernandez-Acenero MJ. Intrauterine candidiasis: report of four cases. Arch Gynecol Obstet. (2008) 278:173-6. doi: 10.1007/s00404-007-0554-7

60. Mazor M, Chaim W, Shinwell ES, Glezerman M. Asymptomatic amniotic fluid invasion with Candida albicans in preterm premature rupture of membranes. Acta Obstet Gynecol Scand. (1993) 72:52-4. doi: 10.3109/00016349309013351

61. Xie HY, Feng D, Wei DM, Mei L, Chen H, Wang X, et al. Probiotics for vulvovaginal candidiasis in non-pregnant women. Cochrane Database Syst Revi. (2017) 11:CD010496. doi: 10.1002/14651858.CD010496.pub2

62. Koumans EH, Sternberg M, Bruce C, McQuillan G, Kendrick J, Sutton $\mathrm{M}$, et al. The prevalence of bacterial vaginosis in the United States, 2001-2004; associations with symptoms, sexual behaviors, and reproductive health. Sex Transm Dis. (2007) 34:864-9. doi: 10.1097/OLQ.0b013e31 $8074 \mathrm{e} 565$

63. Laxmi U, Agrawal S, Raghunandan C, Randhawa VS, Saili A. Association of bacterial vaginosis with adverse fetomaternal outcome in women with spontaneous preterm labor: a prospective cohort study. J Matern Fetal Neonatal Med. (2012) 25:64-7. doi: 10.3109/14767058.2011.565390

64. Taylor BD, Darville $\mathrm{T}$, Haggerty CL. Does bacterial vaginosis cause pelvic inflammatory disease? Sex Transm Dis. (2013) 40:117-22. doi: 10.1097/OLQ.0b013e31827c5a5b

65. Govender L, Hoosen AA, Moodley J, Moodley P, Sturm AW. Bacterial vaginosis and associated infections in pregnancy. Int J Gynaecol Obstet. (1996) 55:23-8. doi: 10.1016/0020-7292(96)02744-0

66. Kurki T, Sivonen A, Renkonen OV, Savia E, Ylikorkala O. Bacterial vaginosis in early pregnancy and pregnancy outcome. Obstet Gynecol. (1992) 80:173-7.

67. Andrews WW, Hauth JC, Cliver SP, Conner MG, Goldenberg RL, Goepfert AR: Association of asymptomatic bacterial vaginosis with endometrial microbial colonization and plasma cell endometritis in nonpregnant women. Am J Obstet Gynecol. (2006) 195:1611-6. doi: 10.1016/j.ajog.2006. 04.010

68. Witkin SS, Mendes-Soares H, Linhares IM, Jayaram A, Ledger WJ, Forney LJ. Influence of vaginal bacteria and D- and L-lactic acid isomers on vaginal extracellular matrix metalloproteinase inducer: implications for protection against upper genital tract infections. MBio. (2013) 4:0046013. doi: $10.1128 / \mathrm{mBio} .00460-13$

69. Centers for Disease Control and Prevention. Sexually transmitted diseases treatment guidelines: bacterial vaginosis (2015). Available online at: http:// www.cdc.gov/std/bv/treatment (accessed November 22, 2019).

70. Bradshaw CS, Vodstrcil LA, Hocking JS, Law M, Pirotta M, Garland SM, et al. Recurrence of bacterial vaginosis is significantly associated with post treatment sexual activities and hormonal contraceptive use. Clin Infect Dis. (2013) 56:777-86. doi: 10.1093/cid/cis1030

71. Sheehy O, Santos F, Ferreira E, Berard A. The use of metronidazole during pregnancy: a review of evidence. Curr Drug Saf. (2015) 10:1709. doi: 10.2174/157488631002150515124548

72. Brocklehurst P, Gordon A, Heatley E, Milan WSJ. Antibiotics for treating bacterial vaginosis in pregnancy. Cochrane Database Syst Rev. (2013) 1:CD000262. doi: 10.1002/14651858.CD000262.pub4

73. Lamont RF, Nhan-Chang CL, Sobel JD, Workowski K, Conde-Agudelo A, Romero R. Treatment of abnormal vaginal flora in early pregnancy with clindamycin for the prevention of spontaneous preterm birth: a systematic review and metaanalysis. Am J Obstet Gynecol. (2011) 205:17790. doi: 10.1016/j.ajog.2011.03.047

74. Ugwumadu A, Manyonda I, Reid F, Hay P. Effect of early oral clindamycin on late miscarriage and preterm delivery in asymptomatic women with abnormal vaginal flora and bacterial vaginosis: a randomised controlled trial. Lancet. (2003) 361:983-8. doi: 10.1016/S0140-6736(03)12823-1

75. Lamont RF, Keelan JA, Larsson PG, Jørgensen JS. The treatment of bacterial vaginosis in pregnancy with clindamycin to reduce the risk of infectionrelated preterm birth: a response to the Danish Society of Obstetrics and Gynecology guideline group's clinical recommendations. Acta Obstet Gynecol Scand. (2017) 96:139-43. doi: 10.1111/aogs.13065

76. Haahr T, Ersbøll AS, Karlsen MA, Svare J, Sneider K, Hee L, et al. Treatment of bacterial vaginosis in pregnancy in order to reduce the risk of spontaneous preterm delivery - a clinical recommendation. Acta Obstet Gynecol Scand. (2016) 95:850-60. doi: 10.1111/aogs.12933

77. Ya W, Reifer C, Miller LE. Efficacy of vaginal probiotic capsules for recurrent bacterial vaginosis: a double-blind, randomized, placebo- controlled study. Am J Obstet Gynecol. (2010) 203:120.e1-e6. doi: 10.1016/j.ajog.2010. 05.023

78. Bodean O, Munteanu O, Cirstoiu C, Secara D, Cirstoiu M. Probiotics-a helpful additional therapy for bacterial vaginosis. J Med Life. (2013) 6:434-6.

79. van de Wijgert JHHM, Verwijs MC, Agaba SK, Bronowski C, Mwambarangwe L, Uwineza M, et al. Intermittent Lactobacilli-containing Vaginal Probiotic or Metronidazole Use to Prevent Bacterial Vaginosis Recurrence: A Pilot Study Incorporating Microscopy and Sequencing. Sci Rep. (2020) 10:3884. doi: 10.1038/s41598-020-60671-6

80. Lev-Sagie A, Goldman-Wohl D, Cohen, Dori-Bachash M, Leshem A, Mor $\mathrm{U}$, et al. Vaginal microbiome transplantation in women with intractable bacterial vaginosis. Nat. Med. (2019) 25:1500-04. doi: 10.1038/s41591-0190600-6

81. Ma D, Chen Y, Chen T. Vaginal microbiota transplantation for the treatment of bacterial vaginosis: a conceptual analysis. FEMS Microbiol Lett. (2019) 366:fnz025. doi: 10.1093/femsle/fnz025

82. Sutton M, Sternberg M, Koumans EH, McQuillan G, Berman S, Markowitz L. The prevalence of Trichomonas vaginalis infection among reproductiveage women in the United States, 2001-2004. Clin Infect Dis. (2007) 45:131926. doi: $10.1086 / 522532$

83. Cotch MF, Pastorek JG II, Nugent RP, Hillier SL, Gibbs RS, Martin DH, et al. Trichomonas vaginalis associated with low birth weight and preterm delivery. Sex Transm Dis. (1997) 24:353-60. doi: 10.1097/00007435-19970700 0-00008

84. Klebanoff MA, Carey JC, Hauth JC, Hillier SL, Nugent RP, Thom EA, et al. Failure of metronidazole to prevent preterm delivery among pregnant women with asymptomatic Trichomonas vaginalis infection. New Eng J Med. (2001) 345:487-93. doi: 10.1056/NEJMoa003329

85. Mann JR, McDermott S, Zhou L, Barnes TL, Hardin J. Treatment of trichomoniasis in pregnancy and preterm birth: an observational study. $J$ Women's Health. (2009) 18:493-7. doi: 10.1089/jwh.2008.0964

86. Gulmezoglu AM, Azhar M. Interventions for trichomoniasis in pregnancy. Cochrane Database Syst Rev. (2011) CD000220. doi: 10.1002/14651858.CD000220.pub2

87. Stringer E, Read JS, Hoffman I, Valentine M, Aboud S, Goldenberg RL, et al. Treatment of trichomoniasis in pregnancy in sub-Saharan Africa does not appear to be associated with low birth weight or preterm birth. S Afr Med J. (2010) 100:58-64.

88. Burtin P, Taddio A, Ariburnu O, Einarson TR, Koren G. Safety of metronidazole in pregnancy: a meta-analysis. Am J Obstet Gynecol. (1995) 172(2 Pt 1):525-9. doi: 10.1016/0002-9378(95)90567-7

89. Caro-Paton T, Carvajal A, Martin de Diego I, Martin-Arias LH, Alvarez Requejo A, Rodriguez Pinilla E. Is metronidazole teratogenic? A meta-analysis. Br J Clin Pharmacol. (1997) 44:179-82. doi: 10.1046/j.1365-2125.1997.00660.x

90. Workowski KA, Bolan GA. Sexually transmitted diseases treatment guidelines, 2015. MMWR Recomm Rep. (2015) 64(RR-03):1-137.

91. Lazenby G, Thompson L, Powell A, Soper, D. Unexpected high rates of persistent trichomonas infection among a retrospective cohort of treated pregnant women. Am J Obstet Gynecol. (2018) 219:638-9. doi: 10.1016/j.ajog.2018.10.077 
92. Trintis J, Epie N, Boss R, Riedel S. Neonatal Trichomonas vaginalis infection: a case report and review of literature. Int J STD AIDS. (2010) 21:6067. doi: $10.1258 /$ ijsa.2010.010174

93. Bagga R, Raghuvanshi P, Gopalan S, Das SK, Baweja R, Suri S et al. A polyherbal vaginal pessary with spermicidal and antimicrobial action: evaluation of its safety. Trans R Soc Trop Med Hyg. (2006) 100:11647. doi: $10.1016 /$ j.trstmh. 2006.01 .008

94. Patel Y, Gopalan S, Bagga R, Sharma M, Chopra S, Sethi S. A randomized trial comparing a polyherbal pessary (a complementary and alternative medicine) with Ginlac-V pessary (containing clotrimazole, tinidazole and lactobacilli) for treatment of women with symptomatic vaginal discharge. Arch Gynecol Obstet. (2008) 278:341-7. doi: 10.1007/s00404-0080568-9
Conflict of Interest: PA is employed by the company Nova IVF Fertility.

The remaining author declares that the research was conducted in the absence of any commercial or financial relationships that could be construed as a potential conflict of interest.

Copyright (c) 2020 Bagga and Arora. This is an open-access article distributed under the terms of the Creative Commons Attribution License (CC BY). The use, distribution or reproduction in other forums is permitted, provided the original author(s) and the copyright owner(s) are credited and that the original publication in this journal is cited, in accordance with accepted academic practice. No use, distribution or reproduction is permitted which does not comply with these terms. 